\title{
Changes in glutamatergic neurotransmission within the migraine cycle
}

\author{
G Cosentino, P Paladino, B Fierro, F Brighina* \\ From The European Headache and Migraine Trust International Congress \\ London, UK. 20-23 September 2012
}

\section{Background}

Although some neurophysiological studies have showed cortical excitability changes during different phases of the migraine cycle, the pathophysiological mechanisms underlying attacks recurrence remain unknown. Here we evaluated the response of the migraine motor-cortex to brief trains of $5-\mathrm{Hz}$ repetitive transcranial magnetic stimulation (rTMS) in order to study, indirectly, presynaptic mechanisms of glutamatergic neurotransmission across the different phases of the migraine cycle.

\section{Methods}

40 migraine with aura (MwA) and 40 migraine without aura (MwoA) patients underwent suprathreshold (130\% of the resting motor threshold) brief trains of 5-Hz-rTMS to the motor-cortex, recording Motor Evoked Potentials (MEPs) at each train stimulus. Patients were studied whatever the phase of the migraine cycle: interictal $(n=51)$, preictal $(n=9)$, ictal $(n=10)$ or postictal $(n=10)$.

\section{Results}

As we previously showed [1], in the interictal phase MEPs decreased significantly in size during $5-\mathrm{Hz}$ trains. A significant greater inhibitory response was recorded during the ictal and post-ictal phase. Conversely, in the pre-ictal phase, we observed a facilitatory response to the trains similar to that of normal subjects. No significant differences were recorded between MwA and MwoA patients.

\section{Conclusions}

Our results support the hypothesis that in migraine a transient increase in intracortical glutamatergic activity could trigger the migraine attack. Inhibitory homeostatic mechanisms of glutamate release could be involved in the resolution of the migraine attack and in preventing further attacks.

Published: 21 February 2013

Reference

1. Brighina F, Cosentino G, Vigneri S, Talamanca S, Palermo A, Giglia G, Fierro $B$ : Abnormal facilitatory mechanisms in motor cortex of migraine with aura. Eur J Pain 2011, 15(9):928-935.

doi:10.1186/1129-2377-14-S1-P126

Cite this article as: Cosentino et al:: Changes in glutamatergic

neurotransmission within the migraine cycle. The Journal of Headache and Pain 2013 14(Suppl 1):P126.
Submit your manuscript to a SpringerOpen ${ }^{\circ}$ journal and benefit from:

- Convenient online submission

- Rigorous peer review

- Immediate publication on acceptance

- Open access: articles freely available online

- High visibility within the field

- Retaining the copyright to your article

Submit your next manuscript at $\mathbf{s p r i n g e r o p e n . c o m ~}$ 